
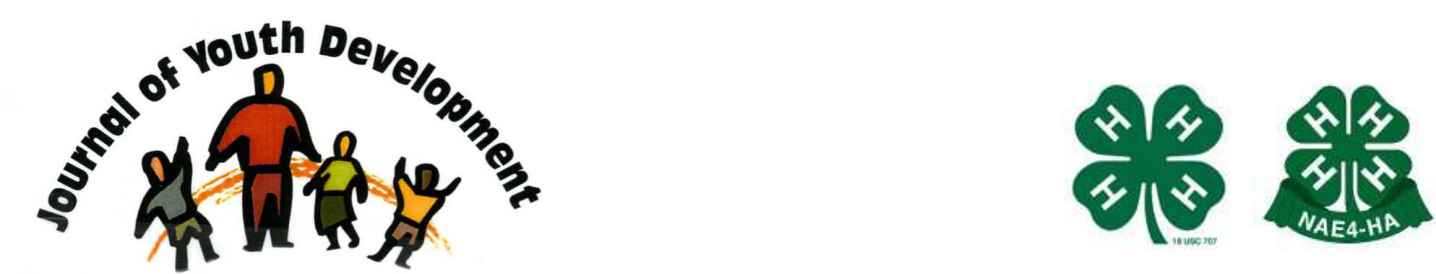

Bridging Research \& Practice

\title{
Why Play Sports? \\ How Organized Sports Participation Can Contribute to the Healthy Development of Adolescent Hispanic Girls
}

\author{
Megan A. Horst \\ Abt Associates, Inc. \\ Cambridge, MA \\ MEGAN HORST@ABTASSOC.COM
}




\title{
JOURNAL OF YOUTH DEVELOPMENT \\ bridging research and practice
}

\section{Why Play Sports? \\ How Organized Sports Participation Can Contribute to the Healthy Development of Adolescent Hispanic Girls}

\author{
Megan A. Horst
}

Abt Associates, Inc.

\begin{abstract}
This study addressed the research question, "What is meaningful to Hispanic girls about their organized sports participation during the first year of high school?" Purposeful sampling (Maxwell, 1996) was used to select 15 9th-grade girls to participate in individual interviews about their organized sport participation. Transcripts were analyzed via inductive coding. Findings showed that organized sports offered Hispanic girls in this sample a venue for healthy youth development, including opportunities for the " $5 \mathrm{C}^{\prime} \mathrm{s}$ " - competence, confidence, connection, character, and caring (Lerner, Fisher, \& Weinberg, 2000). This article highlights the salience of connection, caring, and competence in adolescent Hispanic girls' organized sports experiences. Insights from girls' narratives may help coaches and other educators structure athletic programs to best meet the needs of Hispanic girls during adolescence (AAUW, 1991; Brown, \& Gilligan, 1992; Erkut, Fields, Sing, \& Marx, 1996; Gil, \& Vazquez, 1996; Sadker, \& Sadker, 1994).
\end{abstract}

\section{Introduction}

Adolescence is a time of inevitable change. Adolescents witness the physical maturation of their bodies, experience feelings of sexual desire, develop abstract ways of thinking, forge new relationships and modify old ones, struggle to assert their independence yet maintain connections, and grapple with who they are within their socio-cultural context (Elliott, \& Feldman, 1990). In the context of these multiple sources of change, researchers, clinicians, and parents have traditionally viewed adolescence as a turbulent time (Elliott, \& Feldman, 1990). 
A body of research shows that some girls report dramatically low or lower self-confidence during the early adolescent years (American Association of University Women (AAUW), 1991; Biro, Striegel-Moore, Franko, Padgett, \& Bean, 2006; Brown, \& Gilligan, 1992; Eccles, Barber, Jozefowicz, Malenchuk, \& Vida, 1999; Erkut, Fields, Sing, \& Marx, 1996; Robins, \& Trzesniewski, 2005; Sadker, \& Sadker, 1994; Scales, \& Leffert, 1999), particularly Hispanic girls (AAUW, 1991; Rotheram-Borus, Dopkins, Sabate, \& Lightfoot, 1996). Not all girls, however, demonstrate low self-confidence during adolescence (Hattie, 1992; Offer, \& Schonert-Reichl, 1992), particularly some ethnic minority adolescent girls (Eccles, et al., 1999; Greene, \& Way, 2005).

What is different about the experiences of Hispanic girls who maintain healthy self-confidence during adolescence? Researchers in positive youth development argue that positive, or healthy, attributes can be promoted in a variety of youth contexts, not only limited to school and family life, but also in youth's extracurricular activities (for reviews see Mahoney, Larson, Eccles, \& Lord 2005, and Scales, \& Leffert, 1999). This study offers evidence that organized sports defined as any athletic program (inside or outside of school) with regular practices/instruction, a designated coach, and athletic competitions - is one such context.

Research has supported this notion of "organized" activities, though not limited to sports (Eccles \& Gootmann, 2002; Roth, \& Brooks-Gunn, 2003). Organized activities "are characterized by structure, adult-supervision, and an emphasis on skill-building. These activities are generally voluntary, have regular and scheduled meetings, maintain developmentally based expectations and rules for participants in the activity setting (and sometimes beyond it), involve several participants, offer supervision and guidance from adults, and are organized around developing particular skills and achieving goals" (Mahoney, Larson, Eccles, \& Lord, 2005, p. 4).

\section{Theoretical Framework}

Lerner, Fisher, and Weinberg (2000) have defined healthy youth development according to the "five Cs," a model based on a consensus of researchers, practitioners, and policy-makers. The "five Cs" are:

- competence,

- connection,

- character,

- confidence, and

- caring (or compassion).

Each " $\mathrm{C}$ " is a collection of individual attributes that contribute to overall healthy development and ultimately, from the viewpoint of these researchers, a civil society.

Roth and Brooks-Gunn (2000) have provided more elaborate definitions of the "five Cs":

- competence in academic, social, and vocational areas;

- confidence or a positive self identity;

- connection or healthy relations to community, family and peers;

- character or positive values, integrity, moral commitment; and

- caring and compassion (p. 1). 
This study uses the " $5 \mathrm{Cs}$ " model of health youth development as the theoretical framework for interpreting what is meaningful to adolescent Hispanic girls about their organized sports participation.

\section{Target Population}

Adolescent Hispanic girls are a compelling population to study for multiple reasons:

1. Hispanic girls in particular have demonstrated significant losses in self-esteem during adolescence (AAUW, 1991; Rotheram-Borus, Dopkins, Sabate, \& Lightfoot, 1996).

2. Hispanic girls are underrepresented in the sports literature.

3. Hispanics now represent the largest ethnic minority group in the United States (United States Department of State, 2003), and Hispanic youth are projected to represent 24\% of the elementary and secondary school population by 2020 (Pew Hispanic Center, 2005).

\section{Method}

\section{Participants}

At the end of students' 9th-grade year, semi-structured, in-depth interviews were conducted with 15 9th-grade Hispanic girls ( $M=14.6$ years, $S D=0.43$ years). Girls self-identified their ancestry: Mexican (9), Mexican/Honduran (2), Honduran (2), and unspecified (2). One third of the girls in the interview sample were first generation immigrants (i.e., girl was born outside the United States), and $40 \%$ were second generation (i.e., girl was born in the United States and at least one parent was born outside the United States). These definitions of generational status are modeled on those provided in the Acculturation Rating Scale for Mexican-Americans-II (ARMSA-II) (Cuéllar, Arnold, \& Maldonado, 1995).

All girls attended a public, urban high school in the southwestern United States, serving approximately 1650 students, predominately Hispanic (88\%) and low-income (87\%). All $9^{\text {th }}$ grade students were invited to participate in the overall research project, which included both quantitative (i.e., survey) and qualitative (i.e., interview) components. This research project and related instruments were approved by the Institutional Review Board of Harvard University.

This article reports on findings garnered from the interview data. Purposeful sampling (Maxwell, 1996) was used to select an interview sample representative of a broad cross-section of organized sports participation. Using girls' responses from questionnaires administered to all 9th-grade girls at the beginning and end of the year $(\mathrm{N}=103), 12$ out of 29 organized sports participants were selected for interviews to ensure a range of:

a. types of organized sports;

b. single-sport vs. multi-sport participants;

c. school-based sports participants and community-based sports participants; and

d. length of involvement in organized sports.

Organized sports included any high school teams, private/club teams (e.g., U.S. swim teams), and community/town teams (e.g., YMCA teams).

Twelve of the 15 girls in the interview sample completed at least one season of organized sports participation during 9th-grade. A variety of individual- and team-oriented sports were 
represented $(n=12)$, with soccer $(n=5)$ and volleyball $(n=4)$ most common. Half of the girls played on two or more organized sports teams. Eleven of the 12 girls played on high school teams; two of the 12 girls played on organized teams outside of school.

Three of the 15 girls in the interview sample indicated plans at the beginning of 9th-grade to play on an organized sports team during the school year but in the end quit or did not do so. Though these girls may not have completed the sport season, the interviews provide insight under what conditions these girls were willing and able to play.

\section{Procedure}

\section{Data Collection}

Individual, semi-structured interviews were conducted at the end of girls' 9th-grade year. A semi-structured interview protocol incorporated questions employed in the author's previous research (Horst, 2002). The interview protocol presented girls with a series of questions about the nature and extent of their sports involvement, why they played sports, how sports involvement had influenced their 9th-grade year, and what they appreciated about their organized sports participation. Interviews lasted an average of 60 minutes; interviews were audio-recorded and transcribed.

\section{Data Analysis}

Thematic, inductive coding of interview transcripts served as the primary analytic technique. Inductive codes were developed using a five-step process developed by Boyatzis (1998):

1. Data reduction - Key segments of each transcript were highlighted.

2. Identify themes within each interview transcript - Preliminary "descriptive codes" (Miles \& Huberman, 1994) were documented by the author as well as a team of researchers.

3. Compare themes across interviews - "Descriptive codes" were compared across interviews to identify broader themes, known simply as "codes."

4. Create and record codes - Using the Boyatzis (1998) coding model, each code included:

- A label or name;

- A definition of the theme;

- A description of how to know when the theme occurs;

- A description of qualifications or exclusions to the code; and

- Examples, both positive and negative, to eliminate possible confusion when looking for the theme (p. 31).

Codes were not mutually exclusive; that is, one segment of a transcript could be coded twice if the criteria for both codes were met.

5. Determine code reliability - The author coded all interview transcripts. Trained, independent raters also applied the codebook to selected interview transcripts. Initial inter-rater reliability was supplemented by discussion in order to strengthen the clarity of the codebook and to achieve at least 90\% coding agreement (Miles, \& Huberman, 1994; Ryan, \& Bernard, 2000). 


\section{Results}

In this analysis 48 codes were developed (See Table 1 for a list of all codes). These codes represented what the sample of 9th-grade Hispanic girls discussed as meaningful about their organized sports participation.

Table 1

List of Inductive Codes

\begin{tabular}{|c|c|}
\hline 1. Skill instruction/desire to learn & 25. Being playful \\
\hline Practice, practice, practice & 26. Win/lose attitude \\
\hline 3. Sport achievement & 27. Disappointment \\
\hline 4. Losing & 28. Positive coaching \\
\hline 5. Recognition & 29. Negative coaching \\
\hline 6. Assessment & 30. Punishment/trouble \\
\hline 7. Sport competence & 31. Teamwork \\
\hline 8. High commitment & 32. Responsibility/Leadership \\
\hline 9. Effort & 33. Peer relational connections \\
\hline 10. Proving oneself & 34. Relational tensions \\
\hline 11. Challenge & 35. Frustration \\
\hline 12. Less challenge & 36. Passion \\
\hline 13. Goal setting & 37. Part of me \\
\hline 14. Competitive drive & 38. Release \\
\hline 15. Something to do & 39. Focus \\
\hline 16. Get involved & 40. Control emotions \\
\hline 17. Balancing act & 41. Anxiety \\
\hline 18. Stay out of trouble & 42. Family sports \\
\hline 19. Skill transfer & 43. Family gathering \\
\hline 20. Sport opportunity & $\begin{array}{l}\text { 44. Parent support (or adult extended } \\
\text { family member) }\end{array}$ \\
\hline 21. Fit & 45. Sibling support \\
\hline 22. Details & 46. Parent/family resistance \\
\hline 23. Seriousness & 47. The body \\
\hline 24. Not serious & 48. Sports \& academics \\
\hline
\end{tabular}

In Table 2, the codes are presented by their frequency of occurrence across interviews (High Plus $=30$ or more instances; High $=20-29$ instances; Medium $=10-19$ instances; Low $=9$ or fewer instances). 
Table 2

Frequency of Code Occurrence across Interviews (listed alphabetically)

\begin{tabular}{|l|l|l|l|}
\hline \multicolumn{1}{|c|}{ High Plus (30+) } & \multicolumn{1}{|c|}{ High (20-29) } & Medium (10-19) & \multicolumn{1}{c|}{ Low (0-9) } \\
\hline Assessment & Details & Anxiety & Competitive drive \\
\hline Challenge & Effort & Balancing act & Control emotions \\
\hline Family sports & Positive coaching & Being playful & Family gatherings \\
\hline High commitment & $\begin{array}{l}\text { Practice, practice, } \\
\text { practice }\end{array}$ & Disappointment & Focus \\
\hline Parent support & Recognition & Fit & Get involved \\
\hline $\begin{array}{l}\text { Peer relational } \\
\text { connections }\end{array}$ & Relational tensions & Frustration & Goal setting \\
\hline Sibling support & Something to do & Losing & Less challenge \\
\hline $\begin{array}{l}\text { Skill instruction/ } \\
\text { desire to learn }\end{array}$ & & Negative coaching & Not serious \\
\hline Sport achievement & & Part of Me & Parent resistance \\
\hline Sport competence & & Passion & Proving oneself \\
\hline Teamwork & & Punishment/trouble & Release \\
\hline & & Sport opportunity & Responsibility/ \\
& & Theadership body & Seriousness \\
\hline & & & Skill transfer \\
\hline & & & Sports \& Academics \\
\hline & & & Stay out of trouble \\
\hline & & Win/lose attitude \\
\hline
\end{tabular}

After developing and applying the codebook, the Lerner, Fisher, and Weinberg (2000) model of the " $5 \mathrm{C}^{\prime} \mathrm{s}$ " of healthy youth development - competence, confidence, connection, character, and caring - was useful in clustering the codes. This analysis demonstrated that organized sports are a setting in which healthy developmental can be promoted.

In Table 3, 33 of the 48 codes from the current study are mapped onto the Lerner et al. (2000) " 5 C's" framework of healthy development (Note that ten codes in Table 3 fell under more than one " $\mathrm{C}$ " category - Sport competence, Recognition, Proving oneself, Balancing act, Punishment/ trouble, Losing, Teamwork, Peer relational connections, Parent support, and Sibling support). The codes that did not align with this framework were not indicative of unhealthy development, but rather suggestive of additional important overarching characteristics of healthy development. 
Table 3

Inductive Codes Classified by Lerner, Fisher \& Weinberg (2000)

Model of Healthy Youth Development

\begin{tabular}{|c|c|c|c|c|}
\hline Competence & Confidence & Connection & Character & Caring \\
\hline Sport competence & Something to do & Teamwork & Win/lose attitude & Teamwork \\
\hline $\begin{array}{l}\text { Sport } \\
\text { achievement }\end{array}$ & Sport competence & $\begin{array}{l}\text { Peer relational } \\
\text { connections }\end{array}$ & Teamwork & $\begin{array}{l}\text { Peer relational } \\
\text { connections }\end{array}$ \\
\hline Recognition & Passion & Being playful & Losing & Parent support \\
\hline $\begin{array}{l}\text { Skill instruction/ } \\
\text { Desire to learn }\end{array}$ & Part of me & Positive coaching & $\begin{array}{l}\text { Responsibility/ } \\
\text { leadership }\end{array}$ & Sibling support \\
\hline $\begin{array}{l}\text { Practice, practice, } \\
\text { practice }\end{array}$ & $\begin{array}{l}\text { Stay out of } \\
\text { trouble }\end{array}$ & Family sports & High commitment & \\
\hline $\begin{array}{l}\text { Sports \& } \\
\text { Academics }\end{array}$ & Recognition & Family gatherings & $\begin{array}{l}\text { Punishment/ } \\
\text { trouble }\end{array}$ & \\
\hline Proving oneself & Anxiety & Parent support & Seriousness & \\
\hline \multirow[t]{3}{*}{ Assessment } & Fit & Sibling support & Not serious & \\
\hline & The body & Get involved & Control emotions & \\
\hline & & Balancing act & & \\
\hline
\end{tabular}

In Table 4, the contents of Tables 2 and 3 are combined to create a matrix of the frequency of code occurrence by " $\mathrm{C}$ " cluster. This table highlights that the over $50 \%$ of the codes in each of the " $\mathrm{C}$ " clusters of competence, connection, and caring were "High" or "High Plus" in frequency. In the following section frequently occurring codes within each of these three clusters are described. Quotes from interviews are included where appropriate and as space permits. 
Table 4

Frequency of Code Occurrence by Attribute of Positive Youth Development

\begin{tabular}{|c|c|c|c|c|c|}
\hline & \multicolumn{4}{|c|}{ Frequency of Occurrence } & \multirow[t]{2}{*}{$\begin{array}{l}\text { \% Codes "High } \\
\text { Plus" or "High" }\end{array}$} \\
\hline & High Plus & High & Medium & Low & \\
\hline \multicolumn{5}{|l|}{ COMPETENCE } & \multirow{9}{*}{$6 / 8=75 \%$} \\
\hline Sport competence & $x$ & & & & \\
\hline Sport achievement & $\mathrm{X}$ & & & & \\
\hline Recognition & & $\mathrm{x}$ & & & \\
\hline Assessment & $\mathrm{X}$ & & & & \\
\hline Skill instruction & $\mathrm{X}$ & & & & \\
\hline Practice, practice, practice & & $\mathrm{X}$ & & & \\
\hline Proving oneself & & & & $\mathrm{X}$ & \\
\hline Sports \& Academics & & & & $\mathrm{X}$ & \\
\hline \multicolumn{5}{|l|}{ CONFIDENCE } & \multirow{10}{*}{$3 / 9=33 \%$} \\
\hline Something to do & & $x$ & & & \\
\hline Sport competence & $\mathrm{x}$ & & & & \\
\hline Passion & & & $\mathrm{X}$ & & \\
\hline Part of me & & & $\mathrm{X}$ & & \\
\hline Stay out of trouble & & & & $X$ & \\
\hline Recognition & & $x$ & & & \\
\hline Anxiety & & & $x$ & & \\
\hline Fit & & & $\mathrm{X}$ & & \\
\hline The body & & & $\mathrm{x}$ & & \\
\hline \multicolumn{5}{|l|}{ CONNECTION } & \multirow{11}{*}{$6 / 10=60 \%$} \\
\hline Teamwork & $\mathrm{X}$ & & & & \\
\hline Peer relational connections & $\mathrm{X}$ & & & & \\
\hline Being playful & & & $\mathrm{X}$ & & \\
\hline Positive coaching & & $\mathrm{X}$ & & & \\
\hline Family sports & $\mathrm{X}$ & & & & \\
\hline Family gatherings & & & & $x$ & \\
\hline Parent support & $\mathrm{X}$ & & & & \\
\hline Sibling support & $\mathrm{X}$ & & & & \\
\hline Get involved & & & & $\mathrm{x}$ & \\
\hline Balancing act & & & $\mathrm{X}$ & & \\
\hline \multicolumn{5}{|l|}{ CHARACTER } & \multirow{10}{*}{$2 / 9=22 \%$} \\
\hline Win/lose attitude & & & & $\mathrm{X}$ & \\
\hline Teamwork & $\mathrm{X}$ & & & & \\
\hline High commitment & $\mathrm{X}$ & & & & \\
\hline Responsibility/leadership & & & & $\mathrm{X}$ & \\
\hline Control emotions & & & & $\mathrm{X}$ & \\
\hline Punishment/trouble & & & $\mathrm{X}$ & & \\
\hline Seriousness & & & & $\mathrm{X}$ & \\
\hline Not serious & & & & $\mathrm{X}$ & \\
\hline Losing & & & $\mathrm{X}$ & & \\
\hline \multicolumn{5}{|l|}{ CARING } & \multirow{5}{*}{$4 / 4=100 \%$} \\
\hline Teamwork & $\mathrm{X}$ & & & & \\
\hline Peer relational connections & $\mathrm{X}$ & & & & \\
\hline Parent support & $\mathrm{X}$ & & & & \\
\hline Sibling support & $\mathrm{X}$ & & & & \\
\hline
\end{tabular}




\section{Competence}

Competence in organized sports was one of the most common threads across the interviews with adolescent Hispanic girls who participated in organized sports. Girls repeatedly mentioned that it was important for them to be competent in sports or to work towards attaining competence. Frequently occurring Competence codes included:

- Skill instruction/Desire to learn. For girls who were playing on an organized sports team for the first time or for girls who had played organized sports before but were now learning a new sport, the opportunity to receive skill instruction and to become proficient in the sport was of great importance.

- Sport competence. Some girls were not satisfied with simply knowing how to play; they wanted to achieve a level of proficiency or competency that indicated they were particularly "good" at the sport. For example, Daniela explained how she went from knowing how to play volleyball recreationally to being one of the more skilled players on the team:

I really like volleyball, but I never really knew how to play. We use to just play like, like when we had little family parties. Like we use to play, but I didn't really know how. You know so I wanted to get good at it too. And like my first year (in middle school), I was pretty good. Like, I knew like how to play before I had played in middle school, but it was way different because everything you do like bump, set, spike. And like I didn't know how to do that and I didn't really know what it meant either (laughs). So you know I had to learn that and I learned pretty quick, so I got good at it. And, um I ended up being, like being like one of the good ones, 'cause you know I had like a lot of serves.

- Sport achievement. Perhaps not surprisingly, some of girls' favorite memories from the season were examples of crowing sport achievements - placing in competitions, performing well, or the ultimate experience of sports competence - winning.

- Recognition. Some girls appreciated when they were recognized by others for their sports competence. Laura told about one of her shining moments on the volleyball team:

I was having a good day so I would serve a lot. And I would like serve almost the whole game to 15... Then the audience was like yelling and stuff. You know, like "Laura!" They're like, "Little one!" 'Cause I'm like little. And it was just fun, and then the coach would be like, "Yeah!" And everybody would be cheering and stuff. You know, it doesn't happen a lot, um, cheering at the games.

Recognition also came after the competition. Sports scores and individual achievements were noted on the morning announcements at school, leading to congratulatory remarks from peers throughout the day. Another form of recognition which was particularly meaningful to Ana, a newcomer to organized sports, was earning her varsity letter jacket, which she wore proudly to school.

- Assessment. Throughout interviews, girls frequently assessed their or their team's ability in comparison to that of their teammates or competition. Girls who excelled in their sport had a clear understanding of the extent of their skills and recognized the pivotal roles that they played on their respective teams. 
- Practice, practice, practice. Girls, especially the veteran sports participants, understood the importance of practice in order to achieve sports competence. Veteran sports participants often selected athletics as their elective class in order to have extra practice time and also stayed after school for off-season "open gym" practice. Additionally, some coaches found opportunities for their players to hone their skills at formal sports camps during the summer.

\section{Connection}

Healthy development includes forming positive relationships with family, peers, and community (Lerner, et al., 2000; Roth, \& Brooks-Gunn, 2000). Hispanic girls in this sample repeatedly detailed how sports provided them opportunities to connect with friends and family. The following codes illustrate how organized sports can provide Hispanic girls a forum for Connection:

- Peer relational connections. Peer relationships on and off the field were repeatedly cited as a key feature of their sports participation. Organized sports appeared to facilitate these Hispanic girls' transition into the 9th-grade by providing them with a social network of same-grade and upper-grade friends. For Sandra, who had not attended the middle school that feeds into the high school, this was true:

At first it was kind of easy (making friends)... I got along with the volleyball team 'cause volleyball's kind of right when you enter school, like. And then Laura, she was real like easy-going, you know. And so we just, I don't know we just started always being together. And we do stuff on the weekends and stuff.

Mentoring-type relationships were sometimes formed between upper-grade varsity players and 9th-grade girls in the same sport. These varsity players provided instruction and guidance to the girls in addition to that of the head coach. Although Daniela was a veteran to organized sports, she nonetheless appreciated the attention of senior team members:

It's not like upper class $\left(10^{\text {th }}, 11^{\text {th }}\right.$, or $12^{\text {th }}$ grade) girls like, you know, think they're better or whatever. It's not like that. They're real supportive. Like they try to help you, like in whatever you need.... And I think that was one of the things that made me like get a little bit better 'cause a lot of the upper class girls like, they were like, "Oh no, you have to do it like this." You know, they wouldn't say it in a bad way. They would like, "Just try your best."

- Teamwork. On the playing field girls established and nurtured a special type of relational connection - Teamwork. Girls in this sample talked at length about the sports-related support and encouragement they received from their teammates on a daily basis. Teammate support was particularly important to girls who were new to sports and might need additional, external motivation to keep with a sport. Unfortunately, on a couple of the school sports teams, several girls quit early or midseason leaving their teams scrambling to fill the void. Such events had a significant impact on the sports experience of the remaining players. As described by Sandra, remaining players were keenly aware of the importance of being a dependable teammate as well as a good friend: 
Our first baseman left. ...'cause our coach is real hard on us. But I don't think it's right for them to leave the team. 'Cause you know like, the girls on your team are your friends, you know... And when she left it was like, "Okay, now we don't got no first baseman." You know? Our pitcher, the one pitcher we did have, she left too because of him (the coach).... You depend on that person to always be there. And then, they just leave. You know? I don't think it's right... Stick together.

- Positive coaching. Some coaches served as positive adult figures in these girls' lives. Girls particularly praised the coach of the $9^{\text {th }}$ grade volleyball team who prioritized having fun, skill instruction, and positive reinforcement among a team comprised of many girls who had limited or no volleyball experience. This coach was also a 9th-grade teacher at the school and understood when girls needed to miss practice for tutoring.

- Family sports, Parent support, Sibling support. Girls' narratives about their sports involvement were almost always set in the context of family sports. Family sports participation often functioned as girls' entry point into sports as well as a source of connection for girls with their families, particularly male nuclear and extended family members. Within the context of these relationships, girls received conversation, instruction, training partners, and support. Daniela poignantly described how through sports she connected with her father who had moved to the United States five years prior to the rest of the family:

I guess I kind of grew distant from my dad 'cause I wasn't use to him. ...Like, I started getting real close to him because like I started seeing that him and my mom were having problems, you know, so I was like, "I want to get to know my dad." ...So I started getting along with him, you know, and talking about sports mainly. So I was like, "How do you do this? You know, how do you play this?"

\section{Caring}

Connection and Caring are intimately related in organized sports participation in this sample of adolescent Hispanic girls. In fact, each of the Caring codes in this analysis also falls under the Connection cluster. Although care and compassion may not come to mind as attributes engendered by sports participation, Hispanic girls in this sample provided rich narratives that demonstrated how organized sports can function as a venue in which a girl can develop and display concern for others, as well as be the recipient of care. Frequently occurring Caring codes included:

- Teamwork, Peer relational connections. Girls demonstrated concern for their teammates through verbal encouragement and support. Teammates cheered for each other during races and gave each other "props" for points well played. It can be easy to display care when things are going well, but it is quite another capacity to act compassionately in team settings when players can become frustrated with poor performances or teammate errors. Several girls candidly shared that they had learned how to better support teammates through their sports participation, as Daniela, a veteran to organized sports, explained:

You know, it's not like, "Why did you do that? You're not suppose to do that" (in a huffy tone). Like I have a better attitude towards things like that. Like, "Oh, it's okay. You'll get it next time." Stuff like that, you know. But like before I was like, "Why did 
you do that?!" And now it's like, "It's okay. You'll get it next time." You know, I have like I guess more patience since like you can't win every single game. Since you can't be perfect when you just start a sport. You know I guess sports taught me that - to like, to be patient, you know, and how to get along with other girls.

As girls forged friendships with teammates, their commitment to the sport became intertwined with their commitment to their friends. Girls deeply cared about the impact of their actions on teammates and the team's ability to function. For many girls quitting ultimately was not an option; their concern for the team's and teammates' well-being trumped any personal reasons for quitting.

- Parent support, Sibling support. Girls described their parents and siblings as supportive of their organized sports participation via a wide range of activities. Parents and siblings expressed care for girls' sports involvement by attending games, offering words of encouragement, practicing together, purchasing sports equipment, helping set up for competitions, and participating in the team booster club.

\section{Discussion}

Organized sports participation afforded adolescent Hispanic girls in this sample a wealth of opportunities to acquire and nurture positive developmental outcomes and skills. Using the Lerner, Fisher, and Weinberg (2000) " 5 C's" model of healthy development as a theoretical framework for interpretation, this article provides preliminary evidence for how organized sports can serve as a positive factor in Hispanic girls' adolescent development. Girls' interviews and the corresponding inductive codebook highlight that organized sports provide these adolescent Hispanic girls with opportunities to develop competence, to feel self confident, to connect meaningfully with others, to practice positive character values, and to express care and compassion.

\section{Salient Themes}

Girls in this sample spoke most frequently and extensively about organized sports as a place for competence, connection, and caring, representing three of the " $5 \mathrm{Cs}$ " of healthy youth development (Lerner, et al., 2000). The prevalence of these themes is not surprising given the sports and broader extracurricular participation literature to date. Such research has long and consistently shown that

(a) perceived competence or skill development, and

(b) friendship or affiliation are leading motivations or incentives in girls' (and boys') decisions to become and remain involved in sports (e.g., Csikszentmihalyi, 1975; Erkut, Fields, Sing, \& Marx, 1996; Gill, Gross, \& Huddleston, 1983; Gould, Feltz, \& Weiss, 1985; San Antonio, 2004; Wankel, \& Kreisel, 1985).

Though not labeled as such, research has also demonstrated the importance of care in girls' (and boys') sports experiences. The following factors have shown to be positively related to girls' (and boys') participation in or enjoyment of organized sports:

- Parent support (e.g., low pressure) (Brustad, 1988; Leff, \& Hoyle, 1997, Leff, \& Hoyle, 1995);

- Coaching style (e.g., skill instruction, encouragement) (Smoll \& Smith, 2002); 
- Peer affiliation (e.g., Gould, Feltz, \& Weiss, 1985; San Antonio, 2004); and

- Teamwork (e.g., Gill, Gross, \& Huddleston, 1983).

What is not highlighted within this literature is the salient finding from this study that organized sports can serve as a source of connection and care among Hispanic families. Although organized sports participation could theoretically take time away from the family due to sports practices and competitions, the girls in this study most often described organized (and recreational) sports as a way to spend time together with family through conversation, competition attendance, and extra training or instruction. Of particular note, girls' detailed how through sports they were able to maintain or forge connections with their fathers, brothers, and/or other male family members.

\section{Implications}

Understanding why adolescent Hispanic girls participate in organized sports holds important implications for educators, coaches, parents, and girls. As we broaden and deepen our understanding about what is meaningful to adolescent Hispanic girls about their sports participation, it may be possible to document further how sports can serve as a protective factor during adolescence and to design sports programs that best support girls' needs from a development perspective as well as a cultural perspective.

Given the defining role coaches can play in girls' sporting experiences, and by extension school experiences, keen attention needs to be given to the formal training of coaches. In direct practice, coaches must be able to draw on a range of motivational and instructional strategies in order to work with a variety of players who have different skill levels, experience, and goals.

Beyond sports mechanics, coaches should be required to take coursework in human development so as to be able to recognize the developmental tasks and challenges of their players. For example, given the importance of peer relations during adolescence, coaches should be sure to make time for team bonding both on and off the court.

As demonstrated in this study, organized sports can promote positive attributes and learning experiences, such as competence, confidence, connection, character, and caring. All youth should have access to such opportunities. Yet only $29 \%$ of girls in the $9^{\text {th }}$-grade at the study site participated in organized sports inside or outside of school - a rate $40 \%$ less than Hispanic girls nationally (49\%) (Grunbaum, et al., 2004). This finding may reflect a shortage of club or community-based teams, a lack of interest, differences due to immigration status or ethnicity, or other barriers to access.

Given that sports can foster positive youth development, we should advocate for increasing the number, range, and use of organized sports opportunities in the community, such as through the local park department and youth organizations such as the YMCA. One example would be to create a soccer league that invites youth and adults to participate together so that entire families and communities can share in a sports experience. Another example would be to offer school- or community-based multi-age summer sports camps, perhaps in conjunction with academic enrichment or fine arts programs, to provide youth with structured summer activities and eliminate caretaking responsibilities as a barrier. 
This study underscores that the sporting revolution for girls living in the United States has not been universal in reach. In an era of sports "powerhouses" and elite traveling teams, it has become increasingly vital for a player to be able to demonstrate excellence or talent in sports at an early age. Opportunities to participate on prestigious varsity and club teams are limited, often handled by "cutting" those less able.

In striking contrast, girls in this sample - Hispanic girls of recent immigrant status from a lowincome community in the southwestern United States - could join an organized sports team during 9th-grade with no experience, a tremendous and rare opportunity. Among these girls, there was a greater focus on skill development and opportunity to play than in my previous research with White, middle-to-upper class girls who concentrated heavily on sports achievement and goal attainment (Horst, 2002). Given the increasingly competitive youth sports market, it was quite refreshing to hear one talented, veteran, multi-sport Hispanic girl say that she played basketball simply "for the love of the game."

\section{Limitations and Future Research}

A qualitative study such as this offers distinct advantages in terms of in-depth, rich narratives from girls themselves, but also limits generalizeability. As researchers have pointed out, there are distinct historical and cultural differences among Hispanic subpopulations (e.g., Erkut, \& Tracy, 2002; Marín, \& Marín, 1991). The majority of girls in this sample were of Mexican ancestry; research with other Hispanic populations should be pursued.

Second, this study focused on participation in any organized sports. This inquiry neither targeted specific sports, nor was it representative of all sports. Additionally, girls in this sample primarily played high school sports. Few girls played on club or community-based teams. Based on my analysis of this sample, there also may be important differences between newcomers to organized sports and veteran players that need to be further investigated. Despite these limitations, this study offers rich information regarding what is meaningful to adolescent Hispanic girls about their organized sports participation beyond what is provided by the sports research to date as well as relates these findings to the positive youth development literature.

\section{References}

American Association of University Women (AAUW). (1991). Shortchanging girls, shortchanging America. Washington, DC: Author.

Biro, F.M., Striegel-Moore, R.H., Franko, D.L., Padgett, J., \& Bean, J.A. (2006). Self-esteem in adolescent females. Journal of Adolescent Health, 39, 501-507.

Boyatzis, R.E. (1998). Transforming qualitative information: Thematic analysis and code development. Thousand Oaks, CA: Sage.

Brown, L.M., \& Gilligan, C. (1992). Meeting at the crossroads: Women's psychology and girls' development. New York: Ballantine Books. 
Brustad, R.J. (1988). Affective outcomes in competitive youth sport: The influences of intrapersonal and socialization factors. Journal of Sport \& Exercise Psychology, 10, 307-321.

Csikszentmihalyi, M. (1975). Beyond boredom and anxiety. San Francisco: Jossey-Bass.

Cuéllar, I., Arnold, B., \& Maldonado, R. (1995). Acculturation Rating Scale for Mexican Americans - II: A revision of the original ARSMA scale. Hispanic Journal of Behavioral Sciences, $17,275-304$.

Eccles, J., Barber, B., Jozefowicz, D., Malenchuk, O., \& Vida, M. (1999). Self-evaluations of competence, task values, and self-esteem. In N.G. Johnson, M.C. Roberts, \& J. Worell (Eds.) Beyond appearance: A new look at adolescent girls (pp. 53-83). Washington, DC: American Psychological Association.

Eccles, J.S., \& Gootmann, J.A. (Eds.). (2002). Community programs to promote youth development. Washington, DC: National Academy Press.

Elliott, G.R., \& Feldman, S.S. (1990). Capturing the adolescent experience. In S. S. Feldman \& G. R. Elliott (Eds.), At the threshold: The developing adolescent (pp. 1-13). Cambridge, MA: Harvard University Press.

Erkut, S., Fields, J.P., Sing, R., \& Marx, F. (1996). Diversity in girls' experiences: Feeling good about who you are. In B.J.R. Leadbeater \& N. Way (Eds.), Urban girls: Resisting stereotypes, creating identities (pp. 53-64). New York: New York University Press.

Erkut, S., \& Tracy, A.J. (2002). Predicting adolescent self-esteem from participation in school sports among Latino subgroups. Hispanic Journal of Behavioral Sciences, 24, 409-429.

Gil, R.M., \& Vazquez, C.I. (1996). The Maria paradox: How Latinas can merge Old World traditions with new world self-esteem. New York: GP Putnam's Sons.

Gill, D.L., Gross, J.B., \& Huddleston, S. (1983). Participation motivation in youth sports. International Journal of Sport Psychology, 14, 1-14.

Gould, D., Feltz, D., \& Weiss, M. (1985). Motives for participating in competitive youth swimming. International Journal of Sport Psychology, 16, 126-140.

Greene, M.L., \& Way, N. (2005). Self-esteem trajectories among ethnic minority adolescents: A growth curve analysis of the patterns and predictors of change. Journal of Research on Adolescence, 15, 151-178.

Grunbaum, J.A., Kann, L., Kinchen, S., Ross, J., Hawkins, J., Lowry, R., et al. (2004, May 21). Youth Risk Behavior Surveillance - United States, 2003. Morbidity and Mortality Weekly Report, 53 (No. SS-2). Washington, DC: U.S. Government Printing Office.

Hattie, J. (1992). Self-concept. Hillsdale, NJ: Lawrence Erlbaum. 
Horst, M.A. (2002). Why play sports? Organized sports participation in the lives of adolescent girls. Unpublished qualifying paper, Harvard Graduate School of Education, Cambridge, MA.

Leff, S.S., \& Hoyle, R.H. (1995). Young athletes' perceptions of parental support and pressure. Journal of Youth and Adolescence, 24, 187-203.

Leff, S.S., \& Hoyle, R.H. (1997). The role of parental involvement in youth sport participation and performance. Adolescence, 32, 233-243.

Lerner, R.M., Fisher, C.B., \& Weinberg, R.A. (2000). Toward a science for and of the people: Promoting civil society through the application of developmental science. Child Development, $71,11-20$.

Mahoney, J.L., Larson, R.W., Eccles, J.S., \& Lord, H. (2005). Organized activities as developmental contexts for children and adolescents. In J.L. Mahoney, R.W. Larson, \& J.S. Eccles (Eds.), Organized activities as contexts of development: Extracurricular activities, afterschool, and community programs (pp. 3-22). Mahwah, NJ: Lawrence Erlbaum.

Marín, G., \& Marín, B.V. (1991). Research with Hispanic populations. Thousand Oaks, CA: Sage.

Maxwell, J.A. (1996). Qualitative research design: An interactive approach. Thousand Oaks, CA: Sage.

Miles, M.B., \& Huberman, A.M. (1994). Qualitative data analysis: An expanded sourcebook ( ${ }^{\text {nd }}$ ed.). Thousand Oaks, CA: Sage.

Offer, D., \& Schonert-Reichl, K.A. (1992). Debunking the myths of adolescence: Findings from recent research. Journal of the American Academy of Child and Adolescent Psychiatry, 31, 1003-1014.

Pew Hispanic Center (2005). Hispanics: A people in motion. In Trends 2005 (pp. 71-89). Washington, DC: Author. Retrieved February 26, 2005, from: http://www.pewhispanic.org/site/docs/pdf/HispanicTrends2005.pdf

Robins, R.W., \& Trzesniewski, K.H. (2005). Self-esteem development across the lifespan. Current Directions in Psychological Science, 14, 158-162.

Roth, J., \& Brooks-Gunn, J. (2000). What do adolescents need for healthy development? Implications for youth policy. Social Policy Report, 14, 3-19.

Roth, J.L., \& Brooks-Gunn, J. (2003). What is a youth development program? Identification of defining principles. In R.M. Lerner, F. Jacobs, \& D. Wertlieb (Eds.), Promoting positive child, adolescent, and family development: $A$ handbook of program and policy innovations (Vol. 2) (pp. 197-224). Thousand Oaks, CA: Sage. 
Rotherham-Borus, M.J., Dopkins, S., Sabate, N., \& Lightfoot, M. (1996). Personal and ethnic identity, values, and self-esteem among Black and Latino adolescent girls. In B.J.R. Leadbeater \& N. Way (Eds.), Urban girls: Resisting stereotypes, creating identities (pp. 35-52). New York: New York University Press.

Ryan, G.W., \& Bernard, H.R. (2000). Data management and analysis methods. In N.K. Denzin \& Y.S. Lincoln (Eds.), Handbook of qualitative research (pp. 769-802). Thousand Oaks, CA: Sage.

Sadker, M., \& Sadker, D. (1994). Failing at fairness: How our schools cheat girls. New York: Touchstone.

San Antonio, D. (2004). Adolescent lives in transition: How social class influences the adjustment to middle school. Albany, NY: State University of New York Press.

Scales, P., \& Leffert, N. (1999). Developmental assets: A synthesis of the scientific research on adolescent development. Minneapolis, MH: Search Institute.

Smoll, F.L., \& Smith, R.E. (2002). Coaching behavior research and intervention in youth sports. In F.L. Smoll \& R.E. Smith (Eds.), Children and youth in sport: A biopsychological perspective $2^{\text {nd }}$ ed.) (pp. 211-234).

United States Department of State, Office of International Information Programs, Washington File (2003, January 23). Hispanics replace African Americans as largest U.S. minority group. Retrieved February 12, 2003, from: http://usinfo.state.gov/usa/race/diversity/a012303.htm

Wankel, L.M., \& Kreisel, P.S.J. (1985). Factors underlying enjoyment of youth sports: Sport and age group considerations. Journal of Sport Psychology, 7, 51-64.

(C) Copyright of Journal of Youth Development Bridging Research and Practice. Content may not be copied or emailed to multiple sites or posted to a listserv without copyright holder's express written permission. Contact Editor at: patricia.dawson@oregonstate.edu for details. However, users may print, download or email articles for individual use.

ISSN 2325-4009 (Print); ISSN 2325-4017 (Online) 